\title{
POLITICAS LINGUÍSTICAS E O ENSINO BILÍNGUE PORTUGUÊS-POMERANO EM SANTA MARIA DE JETIBÁ, ESPÍRITO SANTO
}

\author{
Erineu Foerste \\ (UFES) \\ Edenize Ponzo Peres \\ (UFES)
}

Sintia Bausen Küster

(SECEDU)

\section{RESUMO}

Neste trabalho, são apresentadas e discutidas as políticas linguísticas implantadas no Espírito Santo, especificamente no município de Santa Maria de Jetibá, visando à valorização e à manutenção da língua e da cultura pomerana. Em interlocução com algumas produções acadêmicas disponíveis, é historiado o contexto educacional das crianças pomeranas para, em seguida, analisarem-se as consequências da implantação do Programa de Educação Escolar Pomerana, o Proepo, que introduz a educação bilíngue português-pomerano nesse município. Conclui-se que o Proepo é reconhecidamente importante para a valorização dessa língua de imigração, trazendo benefícios principalmente às crianças do campo em fase escolar. Entretanto, sabe-se que o Proepo precisa avançar e que outras medidas de valorização do pomerano devem ser tomadas para garantir a permanência dessa língua nas gerações futuras.

PALAVRAS-CHAVE: Políticas linguísticas; educação bilíngue; pomerano. 


\section{Apresentação}

A partir da primeira metade do século XIX, o Espírito Santo recebeu milhares de imigrantes estrangeiros, sobretudo europeus, que vieram colonizar as terras virgens da região centro-serrana do estado. Chegavam fugindo das guerras internas e externas, bem como da miséria imposta por uma Europa em crise econômica, política e social (FRANZINA, 2006).

A essa época, o Brasil passava por um momento singular em sua história: a iminente abolição da escravatura e a consequente falta de elemento humano para a lavoura. Além desses fatores, havia o intuito do Governo Imperial de embranquecer a população, com base em teorias racistas que imperavam na Europa, no século XIX, e que foram adotadas no Brasil (OLIVEIRA, 2008). Assim, a solução encontrada pelo Governo foi a importação de mão de obra europeia. Para alcançar esse objetivo, o Brasil lançou uma grande campanha no continente europeu, a fim de cooptar famílias que se dispusessem a vir para este país.

Nesse momento, o Espírito Santo se encontrava nas mesmas condições das demais províncias brasileiras, mas vivia uma situação peculiar: sua população era extremamente escassa e concentrada numa estreita faixa litorânea, consequência da proibição de se construírem estradas para o interior, a fim de se preservarem as defesas naturais contra os ladrões de ouro de Minas Gerais (DERENZI, 1974). Portanto, toda a região central do Espírito Santo era coberta por uma densa floresta virgem.

Para essa província vieram, no século XIX, 47.026 imigrantes, sendo 35.033 da Itália setentrional e 4.013 da Alemanha, incluindo-se aí os pomeranos, que correspondiam a $63 \%$ dos imigrantes germânicos (ARQUIVO PÚBLICO DO ESTADO DO ESPÍRITO SANTO, 2014). O total de imigrantes representava cerca de $22 \%$ da população do Espírito Santo, que, em 1900, era de 209.783 pessoas (IBGE, 2010). Por outro lado, esse contingente populacional se concentrava no litoral, como dissemos. Assim, a região centro-serrana era habitada basicamente pelos imigrantes e seus descendentes.

O isolamento a que essa população estava submetida fez com que as diferentes línguas de imigração fossem usadas majoritariamente em suas comunidades até a década de 1960, no caso dos italianos (DERENZI, 1974), ou de 1980, no caso dos pomeranos (BREMENKAMP, 2014). Entretanto, o crescente contato com o português alterou a situação sociolinguística dessas línguas. Atualmente, existem poucas línguas estrangeiras 
no Espírito Santo, com destaque para o pomerano, falado em diversas comunidades do estado. Porém, estudos recentes realizados em Programas de Pós-Graduação da Universidade Federal do Espírito Santo indicam que o português se faz cada vez mais presente nas famílias pomeranas, o que pode colocar em risco a manutenção do pomerano.

Diante do exposto, este trabalho tem por objetivo analisar a situação sociolinguística do pomerano no Espírito Santo, discutindo a importância da implantação do Programa de Educação Escolar Pomerana (Proepo) em Santa Maria de Jetibá - considerado o município mais pomerano do estado - e o que se pode fazer para além dele, visando à manutenção dessa língua. Para isso, faz-se um estudo de caso com base em observação participante e em entrevistas com sujeitos de uma escola de Ensino Fundamental da zona urbana desse município, envolvida como Proepo, além da análise de documentos referentes a esse Programa e à cooficialização do pomerano no estado.

Para a exposição deste trabalho, ele foi dividido em quatro partes, além desta Apresentação. Na seção 2, fazemos um histórico da vida da comunidade pomerana e de sua língua. Na seção 3, apresentamos as políticas públicas que visam à manutenção da língua pomerana, caracterizando o contexto escolar pomerano e o Proepo. Na seção 4, analisamos o alcance dessas políticas e também suas limitações, para, por fim, tecermos nossas considerações finais. Comecemos, então, por esse povo e sua história.

\section{0 povo e a língua pomerana no Espírito Santo}

A imigração pomerana no Espírito Santo começou em 1859 e cresceu no início da década de 1870 . Esses imigrantes eram provenientes de Hinterpommern, um dos dois estados da extinta Pomerânia, uma província prussiana localizada entre as atuais Alemanha e Polônia, países entre os quais foi dividido o território pomerano, após a II Guerra Mundial (RÖLKE, 1996).

Esses imigrantes desembarcaram no porto de Vitória e, por barco, chegaram a Santa Leopoldina, fixando-se ali, no meio da densa mata, a cerca de $50 \mathrm{~km}$ do litoral. Aos poucos, porém, as extensas proles se viram forçadas a buscar novas terras cultiváveis, dentro do Espírito Santo. Também se mudaram para outros estados do país, como Minas Gerais, Paraná e Rondônia. Atualmente, estima-se que haja cerca de 300 mil pomeranos ${ }^{1}$ no Brasil. No Espírito Santo, há cerca de 145 mil, localizados principalmente em treze municípios (CAMPOREZ, 2014). 
A região montanhosa e as matas onde os imigrantes pomeranos passaram a viver dificultavam muito o seu contato com a sociedade espírito-santense até os anos de 1980, quando o interior do estado começou a receber infraestrutura, como rede elétrica, linhas telefônicas, estradas asfaltadas etc. Assim, o atraso na chegada da urbanização contribuiu para o isolamento dos pomeranos e, por conseguinte, para a manutenção de sua língua até os dias atuais. O pomerano é falado em domínios como o lar, a lavoura, o comércio, postos de saúde, igrejas, mutirões e festas. Ainda hoje, muitas crianças, principalmente da zona rural, aprendem a língua portuguesa apenas na escola, conforme atestam os estudos de Mian (1993), Weber (1998), Siller (199), Ramlow (2004), Hartuwig (2011), Bremenkamp (2014), Dettman (2014), Kuster (2015) etc. Na zona urbana, onde predominam populações que empregam o português como língua materna, o pomerano é menos falado, com exceção dos municípios de Santa Maria de Jetibá e Laranja da Terra (CAMPOREZ, 2014).

A tabela 1, adaptada de Bremenkamp (2014, p. 163), exemplifica a situação sociolinguística da língua pomerana na comunidade rural de Caramuru, em Santa Maria de Jetibá.

TABELA 1: Perfil linguistico dos informantes de Caramuru - Santa Maria de Jetibá

$\begin{array}{llllll}\text { Qual(is) língua(s) você fala? } & 09-13 & 14-30 & 31-55 & >55 & \text { TOTAL } \\ & \text { anos } & \text { anos } & \text { anos } & \text { anos } & \text { anos } \\ \text { Apenas pomerano } & 0 & 0 & 0 & 5 & 5 \\ \text { Apenas português } & 0 & 0 & 0 & 0 & 0 \\ \text { Pomerano e português } & 11 & 10 & 5 & 3 & 29 \\ \text { Pomerano, português e alemão } & 0 & 0 & 3 & 2 & 5 \\ \text { Pomerano e alemão } & 0 & 0 & 0 & 1 & 1 \\ & & & & & \\ \text { TOTAL } & 11 & 10 & 8 & 11 & 40\end{array}$

Fonte: Bremenkamp (2014, p. 163, adaptada) 
A partir da Tabela 1, observamos que o pomerano é falado por todos os 40 informantes dessa pesquisa, ao passo que o português como língua única não é falado por nenhum deles. Por outro lado, se chamarmos de bilíngue quem faz uso de duas línguas alternativamente, sem se levar em conta seu nível de proficiência em cada uma delas, seguindo a definição proposta por Weinreich (1970), vemos que o bilinguismo pomerano-português está cada vez mais presente nessa comunidade rural.

Qual é o significado desses dados e de que modo eles podem ajudar a fundamentar políticas públicas para a manutenção da língua pomerana no estado? Esses são os temas da próxima seção.

\section{Políticas públicas de manutenção da língua po- merana no Espírito Santo}

A situação sociolinguística da língua pomerana no Espírito Santo originou, nos últimos anos, uma série de pesquisas que, além de avaliar sua vitalidade em diversas comunidades do estado, retrataram as dificuldades pelas quais passam as crianças pomeranas na escola. Em última instância, essas pesquisas alertaram para a necessidade de manutenção dessa língua.

Os resultados desses estudos geraram duas grandes frentes de ação: a implantação, em 2005, do Programa de Educação Escolar Pomerana, o Proepo, que favoreceu a entrada e o uso da língua pomerana nas escolas de cinco municípios do Espírito Santo; e, em 2007, a cooficialização do pomerano nesses mesmos municípios, favorecendo o seu uso em todos os contextos sociais. Entretanto, neste texto, trataremos apenas do primeiro processo. Antes disso, porém, é preciso analisar a educação escolar nas comunidades pomeranas do Espírito Santo, a fim de que se compreendam os contextos que deram origem a tal Programa.

\subsection{A educação escolar em contexto pomerano}

É fato bastante conhecido que, no Brasil, durante o governo de Getúlio Vargas (1930 a 1945 e 1951 a 1954), os imigrantes tiveram seus direitos de associação e de uso de suas línguas maternas negados pela política nacionalista que imperava à época. Essa política era salvaguardada pelos Decretos-Leis no 406/1938 e n ${ }^{\circ} 3010 / 1938$, que dispunham sobre a entrada de imigrantes estrangeiros no país, e pelo Decreto-Lei $\mathrm{n}^{\circ}$ $1545 / 1939$, que deliberava sobre a adaptação de brasileiros descendentes de imigrantes ao meio nacional. De acordo com o Art. $1^{\circ}$ do Decreto-Lei 
$n^{\circ} 1545 / 1939$, a referida adaptação deveria ser feita por meio "do ensino e pelo uso da língua nacional, pelo cultivo da história do Brasil, pela incorporação em associações de caráter patriótico e por todos os meios que possam contribuir para a formação de uma consciência comum".

Dentre as várias imposições às comunidades de imigrantes, estavam as proibições de: a) haver agrupamentos de estrangeiros de uma mesma nacionalidade em colônias ou núcleos coloniais; b) possibilitar aos estrangeiros assumirem postos de direção em escolas, repartições públicas, núcleos coloniais etc.; c) propagar-se material impresso em língua estrangeira sem autorização prévia do Ministério da Justiça; d) serem ministradas aulas em língua estrangeira - salvo as disciplinas de ensino específico dessas línguas; e) imprimir-se material didático em língua estrangeira; f) ser usada uma língua estrangeira na escola ou mesmo em casa; g) ensinar-se uma língua estrangeira a crianças menores de 14 anos; etc.

Outra determinação da política nacionalista de Vargas foi a criação de escolas rurais, nas comunidades formadas por imigrantes, com professores brasileiros, sob a direção de brasileiros e com a veiculação unicamente da língua portuguesa. Na prática, essa política se mostrou eficaz e duradoura, constituindo-se como um processo relativamente lento, mas ininterrupto até os dias atuais, da imposição da cultura dominante a grupos minoritários.

Em meio a essas ações, a educação voltada para as crianças pomeranas, principalmente as residentes nas zonas rurais, que têm como língua materna o pomerano, sofria um descompasso com a realidade de suas famílias e da vida no campo. Dentre as dificuldades mais preocupantes em relação à escolarização dessas crianças, as pesquisas de Mian, 1993; Weber, 1998; Siller, 1999; Ramlow, 2004; Hartuwig, 2011; Bremenkamp, 2014; Dettmann, 2014; Kuster, 2015; etc. apontam: a) alto índice de reprovação, principalmente nas séries iniciais; b) currículo desvinculado do contexto social; c) contratação de professores que não falavam o pomerano; d) gestores educacionais e equipe pedagógica que desconheciam a realidade campesina e promoviam o fechamento das escolas locais; e) subestimação da capacidade de aprendizagem das crianças; f) exclusão dos alunos das práticas escolares, por eles não compreenderem a língua portuguesa; g) reprodução do mito de que os pomeranos são tímidos.

O que as pesquisas acima evidenciam é que as crianças pomeranas, destacadamente as que vivem em comunidades rurais, sentem-se, na escola, e são vistas pelos profissionais do ensino, no dizer de muitos pais, como 
estranhos ou estrangeiros, pelo fato de a absoluta maioria falar o pomerano no dia a dia e, de súbito, ser forçada a aprender o português. Hartuwig (2011), por exemplo, registra depoimentos de crianças pomeranas em Santa Maria de Jetibá que tinham medo de fazer perguntas ou emitir opiniões referentes ao conteúdo das disciplinas curriculares, por causa da dificuldade de comunicação em português. Algumas das pesquisas citadas igualmente trazem relatos de professoras que se diziam orientadas a proibir as crianças de falar a sua língua materna na sala de aula, sob a alegação de que a função da escola é ensinar a ler e escrever na língua oficial.

Dessa feita, a criança falante de pomerano, ao ingressar na escola, passa a ser submetida a pelo menos duas tarefas gigantescas que emergem do modelo escolar oficial: aprender o português e cumprir com os objetivos do período de alfabetização, ou seja, desenvolver habilidades de leitura e produção de textos escritos na língua portuguesa. E, muitas vezes, isso é feito em detrimento do pomerano. Em consequência dessas atitudes, temos narrativas de famílias que revelam a crescente resistência de seus filhos em falar o pomerano, inclusive dentro de casa, depois de ingressarem na escola. Ao mesmo tempo, há aqueles pais que, mesmo sentindo-se culpados, não ensinam a língua pomerana aos filhos; chegam a confessar que, agindo assim, tentam proteger as gerações mais novas de enfrentar as dificuldades pelas quais eles próprios passaram no período da escolarização, decorrentes do preconceito e da exclusão.

A realidade vivenciada pelas crianças pomeranas e suas famílias, confirmada pelas pesquisas desenvolvidas no contexto da educação escolar do Espírito Santo, originou o desejo de se construir uma escola que valorizasse a língua pomerana e seus falantes. Em princípio,a maioria das famílias entrevistadas propôs uma educação bilíngue, com a introdução não apenas do ensino do pomerano na escola, mas que 50\% das disciplinas fossem transmitidas nessa língua. Por educação bilíngue, entendemos, com Appel e Muysken (1996), um sistema de ensino em que uma língua minoritária exerça um papel de importância no currículo, juntamente com a língua majoritária. Esse tipo de educação traria muitas vantagens para as crianças pomeranas, como o seu desenvolvimento cognitivo, acadêmico e psicológico, e também para a comunidade, já que o ensino dessa língua pode evitar a sua assimilação pelo português e pela cultura dominante, favorecendo o grupo minoritário (APPEL; MUYSKEN, 1996). 
Entretanto, não foi possível concretizar essa ideia, conforme trataremos adiante, mas as reivindicações da comunidade pomerana originaram $o$ Programa Educação Escolar Pomerana, como passamos a apresentar.

\subsection{Programa de Educação Escolar Pomerana - Proepo}

A Constituição Federal do Brasil de 1988 e a Lei de Diretrizes e Bases da Educação Nacional - LDBN 9.394/1996 - resguardam a todos os grupos culturais o direito de preservarem sua língua, seus costumes e sua religião. Assim, a partir da década de 1990, surgiram iniciativas visando à manutenção da língua e da cultura pomerana no Espírito Santo, inspirando-se no movimento indígena, que teve seus direitos assegurados nessa Constituição, e nos resultados das primeiras pesquisas acadêmicas que constatavam as dificuldades das crianças pomeranas ao ingressarem na escola falando somente a sua língua materna.

Dessa forma, começou a ser articulado, pela Secretaria Municipal de Educação de Santa Maria de Jetibá, o Projeto de Educação Escolar Pomerana, o Proepo (HARTUWIG, 2011). Entretanto, o Proepo somente se consolidou em 2005, por meio de uma parceria interinstitucional envolvendo professores e pesquisadores com as Secretarias Municipais de Educação de cinco municípios espírito-santenses: Laranja da Terra, Domingos Martins, Pancas, Santa Maria de Jetibá e Vila Pavão. Até 2007, o Proepo era considerado um Projeto; contudo, diante das discussões realizadas pelos coordenadores do Proepo e os Secretários de Educação dos municípios parceiros, houve um consenso de se mudar a nomenclatura para Progra$m a$, por se acreditar que esse seria um trabalho contínuo e consistente.

O Proepo tem como objetivo geral desenvolver, nas escolas públicas dos cinco municípios, um projeto pedagógico que valorize e fortaleça a cultura e a língua pomerana, representadas por meio das línguas oral e escrita, danças, religião, arquitetura e outras tradições. São também seus objetivos: a) introduzir a educação bilíngue (pomerano e português) nas escolas envolvidas no Programa; b) elaborar material didático-pedagógico a ser utilizado nas aulas de diferentes áreas do conhecimento;c) revelar a importância da língua pomerana e o modo de vida camponês como fatores de identidade étnica e social; etc. (KUSTER, 2015).

Quanto às estratégias de organização, cada município parceiro tem autonomia para desenvolver o currículo de acordo com as necessidades e peculiaridades locais. Em Santa Maria de Jetibá, o currículo é organizado 
para atender alunos da rede municipal nas modalidades da Educação Infantil e do Ensino Fundamental, conforme a lei municipal n ${ }^{\circ} 1376 / 2011$, que dispõe sobre o ensino da língua pomerana nas escolas públicas.

Como dissemos, em seu projeto inicial, o Proepo pretendia ter um currículo bilíngue, com 50\% das disciplinas sendo ofertadas na língua pomerana. Entretanto, devido às dificuldades de se encontrarem docentes pomeranos com tais habilitações, o currículo dispõe apenas de uma hora/ aula semanal para a disciplina Língua Pomerana. As aulas são ministradas por professores regentes de escolas multisseriadas, que estão em tempo integral na sala de aula e ensinam os conteúdos nas duas línguas, quando é possível, mas que também reservam uma aula semanal para a disciplina Língua Pomerana. Quando a escola não dispõe desse docente, ela pode contar com professores itinerantes, contratados pela Prefeitura para atender às escolas que não têm, em seu quadro, um professor regente bilíngue em pomerano-português.

Atualmente, em Santa Maria de Jetibá, todas as escolas da rede municipal são atendidas pelo Proepo, desde a creche até os anos finais do Ensino Fundamental. Assim, quinze professores itinerantes ministram uma aula semanal de língua pomerana em diversas escolas e mais seis professores o fazem na turma regular em que atuam.

$\mathrm{Na}$ Educação Infantil, o trabalho com o pomerano é articulado e consolidado nas diferentes áreas do conhecimento por meio de Projetos Norteadores pautados na Proposta Pedagógica da Secretaria Municipal, de acordo com o Referencial Curricular Nacional para a Educação Infantil. Nos anos iniciais do Ensino Fundamental, o Programa é desenvolvido de forma interdisciplinar, integrado ao currículo instituído, em consonância com os eixos temáticos. Nos anos finais do Ensino Fundamental, a língua pomerana é assegurada por lei como disciplina obrigatória na grade curricular, com uma aula semanalmente.

A fim de garantir a qualidade do ensino de língua pomerana ofertado, as Secretarias de Educação dos municípios participantes instituíram, a partir de 2005, o projeto de formação continuada para os professores do Proepo. Até o final de 2012, todos os docentes envolvidos participavam da formação semanal ofertada pelas Secretarias de Educação, que era intermediada por estudos linguísticos e antropológicos, ministrados pelo prof. Dr. Ismael Tressmann, assessor do Proepo, e pela Coordenação, cuja função é gerenciar o trabalho pedagógico e administrativo do Programa.

Nos anos de 2013 e 2014, a capacitação docente foi interrompida, 
sob a alegação, por parte das prefeituras, de dificuldades financeiras. No entanto, foi retomada no final de 2014, por meio de uma parceria entre as prefeituras, a Escola de Serviço Público do Espírito Santo e Secretaria Estadual de Educação. Também até 2012, era promovido, anualmente, um momento de interlocução entre os docentes dos municípios parceiros, denominado Encontrão do Proepo, em que se expunham as vivências e práticas diárias do trabalho realizado pelos professores. Nos últimos três anos, porém, aconteceu apenas um encontro do grande grupo, em Santa Maria de Jetibá.

O conteúdo programático dos cursos de formação docente estava organizado em duas partes. A primeira consistia em Estudos etnolinguísticos: a) diversidade linguística e cultural pomerana; b) o pomerano: uma língua germânica da subfamília do baixo-saxão oriental; c) o calendário pomerano; d) educação escolar e o trabalho camponês; e) identidade étnica e social, tradição e mudança; e f) música: cantigas de roda e de ninar, instrumentos musicais. A segunda parte abordava o Estudo sistematizado da língua pomerana: a) fonologia, morfologia e sintaxe; b) a gramática descritiva: substantivos, verbos, adjetivos, preposição, partículas e ordem operacional - o verbo em segunda posição na sentença; c) léxico; d) linguística e alfabetização; e) leitura e produção de textos em língua pomerana; e f) narrativas orais e literatura escrita.

Em todos esses anos de atuação, o Proepo vem-se consolidando. Em 2006, foi publicado o Dicionário pomerano (TRESSMANN, 2006a), que contém verbetes levantados e sistematizados a partir de pesquisas etnolinguísticas realizadas em diferentes comunidades pomeranas do Espírito Santo. Essas pesquisas contribuíram, simultaneamente, para a organização de um volume de textos em pomerano com narrativas populares, contadas de geração em geração, além de receitas culinárias, tradições do casamento pomerano, arquitetura, vestimentas, festas etc. Esse material foi disponibilizado no livro Up Pommerisch Sprock (TRESSMANN, 2006b). Ambas as publicações contaram com a parceria da Secretaria de Educação do Espírito Santo e, desde então, têm sido usadas como material de pesquisa e de elaboração de recursos didáticos para o ensino do pomerano nas escolas.

Outros recursos didáticos - jogos educativos, literatura infanto-juvenil, material de pesquisa sobre artesanato pomerano, culinária, fauna e flora, exercícios gramaticais etc. -, assim como toda a proposta do Programa, são preparados conjuntamente pelos professores e pela Coordena- 
ção nos horários semanais de planejamento, sempre partindo da realidade dos próprios docentes e dos alunos. Os planos de aula são construídos com base nos conteúdos das diversas áreas de ensino que compõem a proposta curricular do município e também a partir de temas semestrais propostos pelas pedagogas e professoras da rede municipal. A partir desses temas, são elaborados os projetos pedagógicos desenvolvidos em sala de aula, os quais têm o objetivo de tornar a aprendizagem significativa para os alunos, uma vez que os temas escolhidos são condizentes com a sua realidade.

Dessa forma, percebemos que o Proepo está em constante construção, no que diz respeito à elaboração do material utilizado nas aulas, ao desenvolvimento do programa nas escolas e à sua relação com as comunidades pomeranas. Seus avanços e seus limites são analisados na próxima seção.

\section{Políticas públicas e a manutenção da língua po- merana: limites e perspectivas}

Apesar do pouco tempo de sua entrada em vigor, os efeitos do Proepo para a manutenção do pomerano já se fazem sentir em Santa Maria de Jetibá. A regulamentação do ensino da língua pomerana nas escolas, com o objetivo de fortalecê-la e divulgá-la, representa avanços significativos na esfera educacional e política. No campo educacional, o Proepo representa a oportunidade de os professores pomeranos planejarem sua prática pedagógica com base em conhecimentos históricos, culturais e linguísticos próprios, numa ação que considera a cultura dos alunos. Quanto à dimensão política do Programa, seus objetivos vão além dos que estão descritos nos documentos oficiais, pois os pomeranos buscam o reconhecimento e a garantia do direito de usar a sua língua e vivenciar a sua cultura.

A avaliação positiva do Proepo é evidenciada pelos depoimentos a seguir, registrados por Kuster (2015), que analisa a atuação do Programa a partir de um estudo de caso, em uma escola de Ensino Fundamental da zona urbana de Santa Maria de Jetibá.

Aprendemos números, matemática, escrever, ler, nomes, vocabulário. [...] acho importante aprender a ler e escrever na língua porque fixa essa língua. (Entrevista coletiva realizada com os alunos no dia 06/11/2014. In: KUSTER, 2015, p. 145) 
Acho importante que nas aulas de pomerano a professora resgata histórias e as tradições que fazem parte da cultura do nosso povo. [...] Acho muito importante esse trabalho aqui na escola, a gente não quer que acabe isso, esse trabalho, porque assim a cultura continua, permanece entre nós, porque muitas coisas estão mudando e já se perderam. (Entrevista coletiva com os pais, realizada em 06/12/2014. Idem, p.147)

Pra mim tem grande importância porque dá valor ao pomerano! É uma parte da cultura que está se perdendo com o tempo. É um jeito de trazer a cultura para escola e para os próprios alunos. É uma forma de mostrar a nossa cultura, de que geração somos. (A. C. R. D., diretora da escola. Idem, p. 173)

Acho muito relevante! Não deixa perder esta questão cultural. Porque com a morte de uma língua se perde a identidade de um povo, o conhecimento e a cultura do povo pomerano. (G. A. C. S., professora e coordenadora da escola. Idem, p. 173).

A partir desses relatos, percebemos que o Proepo está atingindo seus objetivos, contribuindo para o debate da questão cultural, com ênfase na língua pomerana. Entretanto, como toda prática social que se encontra em fase de consolidação, o Proepo, ao buscar uma educação escolar diferenciada, precisa progredir; ainda existem muitas lacunas a serem superadas e desafios a serem enfrentados. Entre os principais, podemos citar o currículo, que, atualmente, não é de educação bilíngue, como se espera. De acordo com Appel e Muysken (1996), o currículo vigente, denominado por eles de assimilacionista, está adequado à escola de uma sociedade que se considera monolíngue. Assim, o bilinguismo não é fomentado, por não haver recursos para que o ensino da língua minoritária se amplie na escola.

Portanto, para se chegar a uma educação que propicie a manutenção linguística, a carga horária destinada ao ensino da língua e da cultura pomerana precisa ser aumentada, reservando-se pelo menos $50 \%$ do tempo na escola para as atividades propostas pelo Programa. Os depoimentos a seguir, coletados por Kuster (2015), confirmam essa demanda.

Precisava um pouco mais, uma aula é pouco muito pouco, para aprender melhor. (E. D. F., aluno. In: Kuster, 2015, p. 145)

Deveria ser mais tempo, uma aula é muito pouco (D. D. F., aluno. Idem, p. 145) 
Achamos pouco, deveria ter mais tempo para o pomerano. [...] Wij wille meir pomerisch schaul up'm wek" [Nós queremos mais aulas por semana de pomerano]. (Entrevista coletiva com as mães de alunos da escola, realizada em 06/12/2014. Idem, p. 148).

Um segundo problema a ser solucionado é o reduzido número de professores qualificados para essa tarefa, os quais não são suficientes para abranger todas as escolas do município. Outro desafio a ser enfrentado diz respeito às ferramentas didático-pedagógicas escritas na língua pomerana, que, de acordo com os professores que atuam no Programa, precisam ser sistematizadas, organizadas e editadas em forma de um livro didático. Assim, entendemos que o Proepo foi uma aposta exitosa dentro da perspectiva da valorização e do fortalecimento da cultura e, sobretudo, da língua pomerana, mas ainda tem muito a conquistar.

Por último, sabemos que é preciso atuar junto à própria comunidade, a fim de trabalhar a valorização da língua e da cultura pomerana, independentemente de quaisquer partidos ou mesmo da etnia dos líderes políticos dos municípios participantes do Proepo. Essa opinião é compartilhada por vários autores que trabalham com as questões pomeranas, citados neste artigo, e por seus entrevistados. Como exemplo, temos os depoimentos de professoras atuantes no Programa (KUSTER, 2015, p. 171):

Nós precisamos criar um mecanismo de preservar a língua, porque qualquer língua sofre transformações e sua tendência é diminuir. Por isso, vejo que fortalecer a língua pomerana é conscientizar os filhos, netos e bisnetos com esse espírito de preservação. (M. R. C.).

Penso que se não for trabalhado a valorização mesmo, se deixar de lado vai se perder. Tem que incentivar em escola, igreja... Porque se deixar à vontade ela vai se perder. (G. A. C. S.).

Analisando o panorama político-linguístico atual de Santa Maria de Jetibá, corroboramos as palavras de Bremenkamp (2014, p. 257):

A língua de imigração pomerana passa por um momento crucial e único de sua história. De um lado está a crescente urbanização, o aumento da renda e da escolaridade e o contato mais intenso com outras etnias. De outro, está a crescente valorização étnica, os ganhos políticos da língua, o aumento de seu status, a padronização linguística e o seu ensino formal. Em suma, a língua pomerana vive duas situações que ainda não tinham sido experimentadas pela comunidade linguística: a abertura ao Outro e a valorização. Sem precedentes, é impossível 
antever o que acontecerá porque, em nossa visão, essa situação é imprecisa o suficiente para fazer eclodir tanto a substituição quanto a manutenção.

Decerto, é impossível prever qual o futuro da língua entre os pomeranos, mas, a nosso ver, um passo importante foi dado em Santa Maria de Jetibá, quando o município se preocupou com a situação linguística na região. É importante salientar que isso só foi possível porque a língua estava minimamente equipada (CALVET, 2007); isso se deu, num primeiro momento, por meio da grafia proposta por Ismael Tressmann para o pomerano e, posteriormente, pela divulgação da escrita, favorecida pelo Proepo e pela Lei municipal $n^{\circ}$ 31/2009 (SANTA MARIA DE JETIBÁ, 2009), de cooficialização da língua pomerana, a qual resguarda o direito à comunicação em pomerano dentro do município.

Por fim, é válido lembrar que, apesar de haver algumas iniciativas oficiais isoladas de valorização da língua e da cultura pomerana no Brasil, há que se questionar a ausência de políticas públicas que promovam mais processos investigativos em relação aos pomeranos, com maior valorização de sua história e cultura, na educação escolar ou em outras agendas de promoção cultural, sobretudo no âmbito dos governos estaduais.

\section{Considerações finais}

As pesquisas (cf. JACOB, 1992; MARTINUZZO, 2009; HÖHMANN, 2010; BAHIA, 2011; FOERSTE; SCHÜTZ-FOERSTE; MERLER, 2013; etc.), os filmes e os documentários sobre o pomerano e sua cultura retratam um povo alegre, participativo, solidário e interessado pelo trabalho coletivo. Os pomeranos, independentemente de sua faixa etária ou sexo, participam ativamente tanto da realização de festas comunitárias, casamentos etc. quanto da organização do processo produtivo na agricultura familiar e da construção de pontes, estradas e casas. Assim, o trabalho em mutirão é uma tradição trazida da antiga Pomerânia e permanece atualmente no estado.

No que concerne à língua, as pesquisas centradas nas comunidades pomeranas indicam que a maioria dos pomeranos do Espírito Santo vive no campo e é bilíngue, usando de forma alternada o pomerano e o português. Em se tratando de uma língua de imigração, o processo mais comum é o seu abandono já na terceira geração de imigrantes (WEINREICH, 1970; APPEL e MUYSKEN, 1996; COULMAS, 2005; etc.), o que transforma o pomerano numa notável exceção. Portanto, quando analisa- 
mos a maneira como a língua e a cultura pomerana se mantiveram vivas, resistindo às pressões de substituição pela língua e cultura oficiais e a todas as proibições que lhe foram impostas, percebemos a força e a união desse povo em torno de suas raízes.

Assim, com as discussões aqui feitas, é possível questionar como as parcerias entre professores do Proepo, a sociedade civil e o poder público podem promover e garantir a permanência da língua e da cultura pomerana. Duas medidas importantíssimas foram tomadas, que são o Proepo e a cooficialização do pomerano, garantindo o uso livre da língua por seu povo. Entretanto, como já pontuamos, é preciso fazer mais para que a língua não desapareça: os falantes precisam valorizá-la e querer mantê-la. Portanto, deve haver, por parte dos pomeranos, consciência da importância da preservação de sua língua, a fim de que, a despeito do preconceito e da discriminação que sofrem os seus falantes, ela possa ser transmitida às gerações futuras. Esse é o nosso desafio.

\section{LANGUAGE POLICIES AND THE BILINGUAL TEACHING OF PORTUGUESE-POMERANIAN IN SANTA MARIA DE JETIBÁ, ESPÍRITO SANTO}

\section{ABSTRACT:}

In this study, the language policies implemented in the State of Espírito Santo, specifically in the municipality of Santa Maria de Jetibá, with the purpose of valuing and maintaining the Pomeranian language and culture, are presented and discussed. With the support of some available references about the educational context of the Pomeranian children, a historical presentation is offered, followed by an analysis of the consequences of the implementation of the Program of Pomeranian School Education - the Proepo in the state, which introduces the Portuguese-Pomeranian bilingual education in this municipality. It is argued that the Proepo is recognised as important for the immigration language valorization, bringing many benefits mainly for the school-age children living in rural areas. However, it is known that the Proepo needs to move forward and that other measures for the appreciation of the Pome- 
ranian language should be taken in order to ensure the permanence of the language for future generations.

KEYWORDS: Language policies; bilingual education; pomeranian language.

\section{REFERENNCIAS}

APPEL, R.; MUYSKEN, P. Bilingüismo y contacto de lenguas. Tradução de Anxo M. Lorenzo Suárez y Clara I. Bouzada Fernández. Barcelona: Ariel, 1996. ARQUIVO PÚBLICO DO ESTADO DO ESPÍRITO SANTO. Imigrantes: estatísticas. Disponível em: <http://www.ape.es.gov.br/imigrantes/html/estatisticas. html> Acesso em 16 dez. 2014.

BAHIA, J. O tiro da bruxa: identidade, magia e religião entre os camponeses pomeranos do estado do Espírito Santo. Rio de Janeiro: Garamond, 2011.

BEMENKAMP, E. Análise sociolinguística da manutenção da língua pomerana em Santa Maria Jetibá, Espírito Santo. 2014, 291f. Dissertação (Mestrado em Linguística) - Programa de Pós-Graduação em Estudos Linguísticos, Universidade Federal do Espírito Santo, Vitória, 2014.

BRASIL. Decreto-Lei no 406, de 04 de maio de 1938. Dispõe sobre a entrada de estrangeiros no território nacional. Diário Oficial da República Federativa do Brasil, Rio de Janeiro, 06 mai. 1938. Disponível em: <http://www2.camara.leg. br/legin/fed/declei/1930-1939/decreto-lei-406-4-maio-1938-348724-publicacaooriginal-1-pe.html>. Acesso em: 02 dez. 2015.

BRASIL. Decreto $n^{\circ} 3.010$, de 20 de agosto de 1938. Regulamenta o decreto-lei n. 406, de 4 de maio de 1938, que dispõe sobre a entrada de estrangeiros no território nacional. Diário Oficial da República Federativa do Brasil, Rio de Janeiro, 22 ago. 1938. Disponível em: <http://www2.camara.leg.br/legin/fed/decret/1930-1939/decreto-3010-20-agosto-1938-348850-publicacaooriginal-1-pe. html>. Acesso em: 02 dez. 2015.

BRASIL. Decreto-Lei no 1545, de 25 de agosto de 1939. Dispõe sobre a adaptação ao meio nacional dos brasileiros descendentes de estrangeiros. Diário Oficial da República Federativa do Brasil. Rio de Janeiro, 28 jul. 1939. Disponível em: $<$ http:// www2.camara.leg.br/legin/fed/declei/1930-1939/decreto-lei-1545-25-agosto-1939-411654-publicacaooriginal-1-pe.html>. Acesso em: 02 dez. 2015.

CALVET, L.J. As políticas linguísticas. São Paulo: Parábola Editorial: IPOL, 2007. 
CAMPOREZ, P. A luta para manter viva a tradição. Gazetaonline. Vitória,16 jul. 2014. Disponível em: <http://agazeta.redegazeta.com.br/_conteudo/2014/07/ noticias/cidades/1492216-a-luta-para-manter-viva-a-tradicao.html $>$. Acesso em: 17 jul. 2014.

CASTELlUBER, A. Ensino primário e matemática dos imigrantes e descendentes germânicos em Santa Leopoldina, Espírito Santo, Brasil (1857-1907). 2014, 258f. Tese (Doutorado em Educação) - Programa de Pós-Graduação em Educação, Universidade Federal do Espírito Santo, Vitória, 2014.

COULMAS, F. Sociolinguistics: the study of speakers' choices. Cambridge: Cambridge University Press, 2005.

DERENZI, L. S. Os italianos no Espírito Santo. Rio de Janeiro: Artenova, 1974.

DETTMANN, J. Práticas e saberes da professora pomerana: um estudo sobre interculturalidade, 2014, 190f. Dissertação (Mestrado em Educação) - Programa de Pós-Graduação em Educação, Universidade Federal do Espírito Santo, Vitória, 2014.

FOERSTE, E.; SCHÜTZ-FOERSTE, G. M.; MERLER, A. Educação do campo e culturas: uma discussão sobre pedagogias alternativas. In: Visioni Latinoamericane, n. 8, p. 30-41, 2013. Disponível em: <http://www.openstarts.units.it/dspace/ handle/10077/8314>. Acesso em: 04 jul. 2013.

FRANZINA, E. A grande emigração: o êxodo dos italianos do Vêneto para o Brasil. Tradução de Edilene Toledo e Luigi Blondi. Campinas: Editora da Unicamp, 2006 [1976].

HARTUWIG, A. V. G. Professores(as) pomeranos(as): um estudo de caso sobre o Programa de Educação Escola Pomerana - PROEPO - no município de Santa Maria de Jetibá/ES. 2011, 197f. Dissertação (Mestrado em Educação) - Programa de Pós-Graduação em Educação, Universidade Federal do Espírito Santo, Vitória, 2011.

HÖHMANN, B. Sprachplanung und Spracherhalt innerhalb einer Pommerischen Sprachgemeinschaft: eine soziologuistische Studie in Espirito Santo - Brasilien. Berlin: Peterlang, 2010.

INSTITUTO BRASILEIRO DE GEOGRAFIA E ESTATÍSTICA - IBGE. Sinopse do censo geográfico 2010. Disponível em: $<$ http://www.censo2010.ibge.gov. br/sinopse/index.php?dados $=4 \& u f=00>$. Acesso em: 30 mar. 2015.

JACOB, J. K. A imigração e aspectos da cultura pomerana no Espírito Santo. Vitória: Departamento Estadual de Cultura, 1992. Volume 3. (Coleção Memórias). KUSTER, S. B. Cultura e língua pomeranas: um estudo de caso em uma escola do Ensino Fundamental no município de Santa Maria de Jetibá - Espírito Santo 
- Brasil. 2015, 253f. Dissertação (Mestrado em Educação), Programa de Pós-Graduação em Educação, Universidade Federal do Espírito Santo, Vitória, 2015. MARTINUZZO, J. A. Germânicos nas terras do Espírito Santo. Tradução de Helmar Reinhard Rölke. Vitória: Governo do Estado do Espírito Santo, 2009.

MIAN, B. G. Educação de filhos de imigrantes alemães no Espírito Santo: um processo pouco explorado. 1993, 168f. Dissertação (Mestrado em Educação) - Programa de Pós-Graduação em Educação, Universidade Federal do Espírito Santo, Vitória, 1999.

OLIVEIRA, J. T. História do estado do Espírito Santo. 3. ed. Vitória: Arquivo Público do Estado do Espírito Santo, 2008. Volume 08. (Coleção Canaã). Disponível em: <http://www.ape.es.gov.br/index2.htm>. Acesso em 05 mar. 2014.

RAMLOW, L. Conflitos no processo de ensino-aprendizagem escolar de crianças de origem pomerana: diagnóstico e perspectiva.2004, 125f. Dissertação (Mestrado em Educação) - Programa de Pós-Graduação em Educação, Universidade Federal do Espírito Santo, Vitória, 2004.

RÖLKE, H. R. Descobrindo raízes: aspectos geográficos, históricos e culturais da Pomerânia. Vitória: UFES/Secretaria de Produção e Difusão Cultural, 1996.

SANTA MARIA DE JETIBÁ (Prefeitura). Lei no 031, de 04 jun. 2009. Dispõe sobre a cooficialização da língua pomerana no município de Santa Maria de Jetibá. Disponível em: <http://www.ipol.org.br/ler.php?cod=604>. Acesso em: 07 jun. 2013.

SILLER, R. R. A constituição da subjetividade no cotidiano da Educação Infantil. 1999, 214f.Dissertação (Mestrado em Educação) - Programa de Pós-Graduação em Educação, Universidade Federal do Espírito Santo, Vitória, 1999.

TRESSMANN, I. Da sala de estar à sala de baile: estudos etnolinguísticos de comunidades camponesas pomeranas do estado do Espírito Santo. 2005, 335f. Tese (Doutorado em Linguística) - Programa de Pós-Graduação em Linguística, Universidade Federal do Rio de Janeiro, Rio de Janeiro, 2005.

$2006 a$.

Dicionário enciclopédico pomerano-português. Vitória: Sodré,

Upm Land: Up Pommerisch Sprok. Vitória: Sodré, 2006 b.

WEBER, M. G. A escolarização entre descendentes pomeranos em Domingos Martins. 1998, 315f. Dissertação (Mestrado em Educação) - Programa de Pós-Graduação em Educação, Universidade Federal do Espírito Santo, Vitória, 1998.

WEINREICH, U. Language in contact: findings and problems. Paris: The Hague Mouton, 1970. 


\section{NOTAS}

${ }^{1}$ A identidade pomerana remete à história desse povo. Devido à manutenção da língua ancestral e de suas tradições, como o modo típico de construir casas, de realizar rituais de casamentos, batizados e enterros, de educar seus filhos etc., esse povo foi reconhecido como Povo Tradicional Pomerano pelo Decreto 6.040/2007.

Recebido em: 15 de janeiro de 2016

Aceito em: 25 de abril de 2016 